\title{
An Integrated Knowledge Management Capabilities Framework for Assessing Organizational Performance
}

\author{
Abdel Nasser H. Zaied \\ Vice-dean for Education and Students Affairs \\ College of Computers and Informatics, Zagazig University, Egypt \\ E-mail: nasserhr@zu.edu.eg, nasserhr@gmail.com \\ Phone: +201008388588
}

\begin{abstract}
In the present aggressive world of competition, knowledge management strategies are becoming the major vehicle for the organizations to achieve their goals; to compete and to perform well. Linking knowledge management to business performance could make a strong business case in convincing senior management of any organization about the need to adopt a knowledge management strategy. Organizational performance is, therefore, a key issue and performance measurement models provide a basis for developing a structured approach to knowledge management. In this respect, organizations need to assess their knowledge management capabilities and find ways to improve their performance. This paper takes these issues into account when study the role of knowledge management in enhancing the organizational performance and consequently, developed an integrated knowledge management capabilities framework for assessing organizational performance. The results show that there is positive correlation between knowledge management capabilities and organizational performance. The results also show that the proposed framework can be used to assess organizational performance and also can be used as decision tool to decide which knowledge management capability should be improved.
\end{abstract}

Index Terms - Knowledge Management Framework; Organizational Performance; Knowledge Management Capabilities

\section{Introduction}

Because of the increasing interests on knowledge management (KM), various researches had been accomplished. Most researches had dealt with the relationship of knowledge management infrastructure, processes or performance in isolation ${ }^{[1]}$; some researchers had focused on the relationship between knowledge management infrastructure and knowledge management processes, and others had concentrated on the relationship between knowledge management capabilities and organizational performance ${ }^{[2]}$. Several studies had proposed 'KM performance' models to describe the performance improve between the enterprise's current capability and the capabilities improve by KM. Gold, et al. indicated how effectively KM resources are being used to leverage organizational capability ${ }^{[3]}$. Fan, et al. divided Knowledge process capability into acquisition, conversion, application, and protection ${ }^{[4]}$. Aujirapongpan, et al. synthesized and proposed the indicators of knowledge management capability (KMC) in different knowledge management $(\mathrm{KM})$ processes to assess KM effectiveness ${ }^{[5]}$. Whereas, Chang \& Chuang ${ }^{[6]}$ studied the effective KM processes from the roles of infrastructure capability and business strategy.

Accordingly, an integrated view of knowledge management is missing and how to perform knowledge management to improve organizational performance is not clear. In order to alleviate these limitations of the previous research, this study analyzes the previous studies and proposes an integrated knowledge management capabilities framework for assessing organizational performance. This framework was tested empirically to investigate the correlation between knowledge management infrastructure; knowledge management processes and organizational performance and examine its validity in assessing organizational performance based on knowledge management applications.

The remainder of this paper is organized as follows. Section 2 presents KM components, whereas, section 3 presents KM performance models. Section 4 describes the proposed KM framework. In Section 5, we apply this framework and in section 6 we discuss the results. Finally, we conclude with summaries of this work.

\section{Knowledge Management}

Definitions of knowledge management (KM) abound in the management literatures. Knowledge management involves the panoply of procedures and techniques used to get the most from an organization's tacit and codified know-how ${ }^{[7]}$. Filemon \& Uriarte ${ }^{[8]}$ defined $\mathrm{KM}$ as the strategy and processes to enable the creation and flow of relevant knowledge throughout the business to create organizational, customer and consumer value. Finally, it can be defined as the strategies and processes designed to identify, capture, structure, value, leverage, and share an organization's intellectual assets to enhance its performance and competitiveness. 


\subsection{Knowledge Management Components}

Knowledge management (KM) has captured the attention of organizations as one of the most promising ways for organizations to succeed in the information age.

\subsubsection{Knowledge Management Infrastructure Capabilities}

The knowledge management infrastructures are the mechanism for the organization to develop its knowledge and also to stimulate the creation of knowledge within the organization as well as the sharing and protection of it. Yeh et al. ${ }^{[8]}$ defined it as necessary building blocks in the improvement of the effectiveness of activities for knowledge management in an organization.

\subsubsection{Knowledge-based structure}

Knowledge-based structure refers to the extent of an organization's structural disposition toward encouraging knowledge-related activities. The structure must be appropriate to the organization in order to adapt to an ever-changing environment ${ }^{[1],[2],[4],[6],[9-16]}$.

\subsubsection{Knowledge-based technology}

Knowledge-based technology is defined as the technical systems within an organization, which determine how knowledge travels throughout the enterprise and how knowledge is accessed. The implementation of knowledge management technologies without ensuring that the organizations employees are well informed about the organization's overall goals and objectives, and how this technology can facilitate the success of these goals, will lead to disappointing returns on the technology investment [1],[2-6,[8-9],[12-16]

\subsubsection{Knowledge-based human resources}

Knowledge-based human resource describes the extent to which employees specialize in a particular domain and demonstrate the capability of applying that knowledge to interact with others. Since, people are the exclusive creators of knowledge, managing knowledge is managing people, and managing people is managing knowledge ${ }^{[3],[6],[10-12],[4],[16]}$.

\subsubsection{Knowledge-based culture}

Culture incorporates a set of shared values, norms and beliefs, mainly implicit, that the members of an organization possess. Culture defines not only what knowledge is valued, but also what knowledge must be kept inside the organization for sustained innovative advantage ${ }^{[1],[3-6],[9-15],[16]}$.

\subsubsection{Knowledge Management Process Capabilities}

The knowledge management processes is defined as the managerial processes which develop, transfer, transmit, store and apply knowledge, as well as providing the members of the organization with real information to react and make the right decisions, in order to attain the organization's goals.

\subsubsection{Knowledge Acquisitions}

Knowledge acquisition is a process that covers the activities of the accessibility, collecting and application of acquired knowledge. It also refers to how knowledge is acquired from various external and internal sources [3-5],[13],[15],[18-21]

\subsubsection{Knowledge Conversions}

Knowledge acquired from either external or internal sources is ineffective unless it is converted into useful and applicable forms to improve productivity and business operations. Therefore, Conversion is an important factor in process capability ${ }^{\text {[4],[15],[18-19],[22-23] }}$.

\subsubsection{Knowledge Applications}

Knowledge application is a focal element in knowledge management process. The value of individual and organizational knowledge resides primarily on its application. The application of knowledge enables organizations continuously to translate their organizational expertise into embodied products ${ }^{[1],[4-5],[12-13],[15],[18-19],[23-25]}$.

\subsubsection{Knowledge Protections}

Security is always the major concern in any organization's management information systems. Protecting corporate knowledge requires clear but detailed policies to ensure the knowledge asset is in its safe state at all times. The enterprises need to assure their organizational knowledge is kept safely and accessed only by authorized personnel. Protection of knowledge asset is an essential task in the organization's KM implementation ${ }^{[3-4],[13],[15],[18],[26] .}$

\subsubsection{Knowledge Storing}

Knowledge can be stored within the organization 'organization memory' and include physical resources (like written documentation, structured information stored in electronic databases, codified human knowledge stored in expert systems, documented organizational procedures and processes) as well as non-physical resources or can be found outside of the organization ${ }^{[1],[5-6],[9],[17]}$.

\subsubsection{Knowledge Management Functions}

Argote, et al. ${ }^{\text {[27] }}$ defined knowledge management functions as the degree to which the organization creates; shares and utilize knowledge resources across functional boundaries.

\subsubsection{Knowledge Creation}

This comprises activities associated with the entry of new knowledge into the system, and includes knowledge development, discovery and capture.

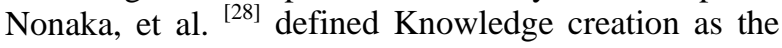
process of making available and amplifying knowledge created by individuals as well as crystallizing and connecting with an organizations' knowledge system. 
The creation of knowledge across functional boundaries requires the capability to generate new applications from existing knowledge and to exploit the unexplored potential of new skills ${ }^{[5],[10],[12],[28-29]}$.

\subsubsection{Knowledge Sharing}

The ability of sharing and distributing knowledge resources across functional boundaries enables the organization to fundamentally change its business processes. The sharing of knowledge resources not only facilitates cross-functional interaction but also allows the sharing of knowledge repositories among process participants, thereby allowing greater collaboration and understanding of the entire process rather than having fragmented parts of the process $[1],[6],[9],[12]$.

\subsubsection{Knowledge Utilizations}

This includes the activities and events connected with the application of knowledge to business processes. Knowledge utilization refers to the degree to which the organization applies the knowledge resources that are shared across functional boundaries. It allows the organization to reap returns on its knowledge resource ${ }^{[1],[5],[27]}$.

\section{Knowledge Management Performance Models}

Performance measurement is one of most important management activities "what you measure is what you get". Performance measurement becomes the basis of strategy establishment and achievement in the future because it can definitely bring a company's vision and strategic target to all organization members as well as CEOs, and performs a role that makes efficient internal business processes possible. There are many researches reveal that corporate performance is significantly influenced by the KM activities [2],[5-6],[9-12],[16],[20],[30-34]

The evaluation of knowledge management (KM) performance has become increasingly important since it provides the reference for directing the organizations to enhance their performance and competitiveness. Many scholars had attempted to measure the contribution of the KM by different models like Lee \& Choi ${ }^{[18]}$; Chang \& Chuang ${ }^{[9]}$; Fan, et al. ${ }^{[4]}$; Gold, et al. ${ }^{[3]}$; Lee \& Lee ${ }^{[2]}$; Liao \& Chuang ${ }^{[11]}$ and Zaim, et al.

Recently, Smith, et al. [15] examined the relationship between knowledge management capabilities and organizational effectiveness utilizing a model developed by Gold, et al. ${ }^{[3]}$. They also attempted to link the knowledge management capabilities to the business strategy postulating a further improvement organizational effectiveness. Theriou, et al. ${ }^{[16]}$ identified and discussed the critical success factors or enablers that determine the KM effectiveness within organizations, which in turn influence the total performance of the firm. Enabler factors include leadership, culture, technology, KM strategy, and people. Firm performance includes market share, and profitability.

In 2011, Mills \& Smith ${ }^{[13]}$ evaluated the impact of specific knowledge management resources (i.e. knowledge management enablers and processes) on organizational performance. Knowledge management capabilities divided into knowledge infrastructure capability and knowledge process capability. Also, Bhatti, et al. ${ }^{[35]}$ presented a conceptual framework model of process, intellectual capital, culture and strategy (PICS) for successful implementation of knowledge management. They concluded that the effective utilization of knowledge will not only create competitive advantage but also improve organizational performance.

\section{Proposed Knowledge Management Performance Framework}

Over the past several years, a number of authors had proposed a variety of approaches for classifying the tools that typically comprise knowledge management systems. This is not the first attempt to develop a framework for organizing and understanding knowledge management tools. This paper provides a framework for characterizing the knowledge management capabilities and assessing organizational performance capabilities. In accordance with the models proposed by Aujirapongpan, et al. ${ }^{[5]}$; Chang \& Chuang ${ }^{[6]}$; Fan, et al. ${ }^{[4]}$ and Gold, et al. ${ }^{[3]}$, an integrated knowledge management capabilities framework for assessing organizational performance was developed. The framework assumes that organizational performance affected by organization knowledge management applications (infrastructure capabilities; process capabilities and functions). Five dimensions were selected to measure knowledge management process capabilities; these dimensions are acquisition, conversion, application, protections and storing.

Also, four dimensions were selected to measure knowledge management infrastructure capabilities these dimensions are technology, structure, culture and human resources. Seven indicators were proposed to measure organizational performance improvement opportunities through three main functions (creation, sharing and utilization) as shown in figure1. 


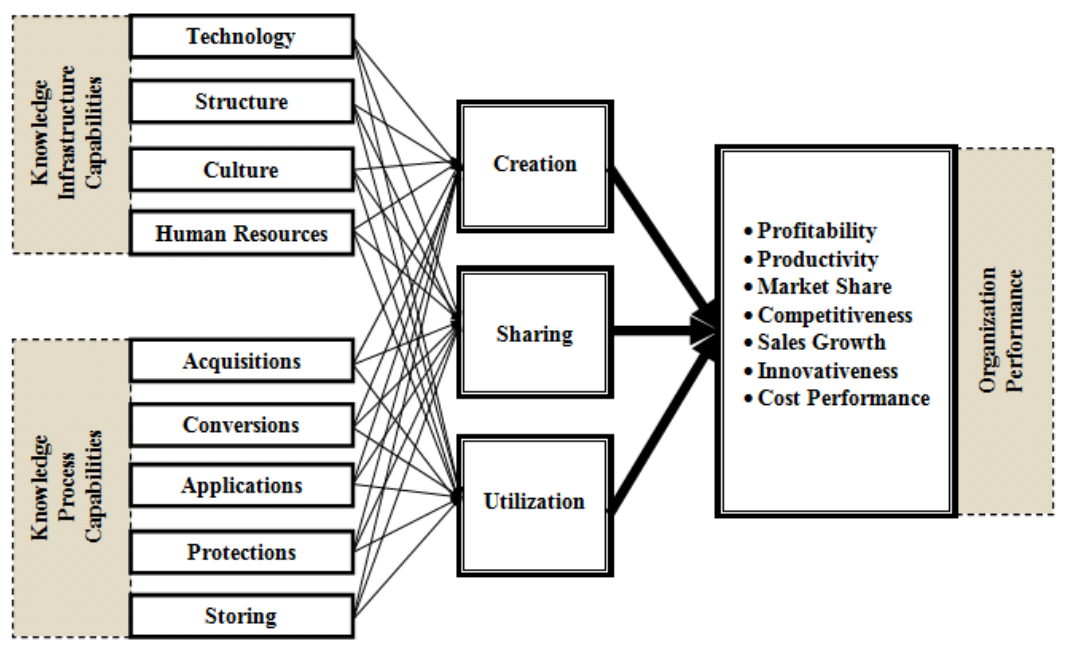

Fig 1: Proposed Knowledge Management Performance Models

The proposed framework can be expressed as follows:

$$
(O P) \equiv(K M I+K M P) * K M F
$$

$(O P)=m((K M I+K M P) * K M F))$

$K M I=\sum_{i=t}^{4}\left(X_{i} * 4\right) / 4$

$K M P=\sum_{f=1}^{\delta}\left(Y_{f} * I_{f}\right) / 5$

$K M F^{\prime}=\sum_{k=1}^{s}\left(Z_{k} * I_{k}\right) / 3$

From equations $1 ; 2 \& 3$, the general equation is as follows:

$a P=m\left[\sum_{i=1}^{4}\left(X_{i} * E_{i}\right) / 4+\sum_{i=1}^{8}\left(Y_{i} * L_{i}\right) / 5+\sum_{k=1}^{8}\left(Z_{k} * I_{k}\right) / 3\right] \ldots$

Where:

$O P=$ Organizational Performance

$K M I=$ Knowledge Management Infrastructure

$K M P=$ Knowledge Management Process

$K M F=$ Knowledge Management Functions

$X_{i} \quad=$ mean of knowledge management infrastructure dimensions

$Y_{j} \quad=$ mean of knowledge management process dimensions

$Z_{k} \quad$ = mean of knowledge management functions dimensions

$I_{i}, I_{j}, I_{k}=$ degree of importance of KM infrastructure; process \& functions dimensions

$m$ = Correction factor depends on organization type (should be calculated in the first time when using this framework) 


\section{Research Methodology}

The main objective of this work is to investigate the correlation between knowledge management capabilities (infrastructure; processes and functions) organizational performance and propose an integrated knowledge management capabilities framework for assessing organizational performance. To fulfill the objective and achieve the goal, a questionnaire was designed to collect the required information.

\subsection{Questionnaire Design}

The questionnaire was designed based on Gold, et al.

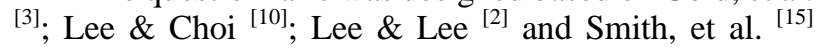
models. Several professors and IS professionals were interviewed to modify the statements, the final questionnaire consists of nineteen dimensions with eighty six statements (24 to measure KM infrastructure, 30 to measure KM process, 18 to measure KM functions and 14 to measure organizational performance) as shown in Appendix (I).

The participants were asked to rate their perception towards the knowledge management level within their organizations on a five-point Likert-type scale with anchors from "5- Strongly agree" to "1- Strongly disagree" and the relative importance for each KM applications dimensions.

\subsection{Research Sample and Questionnaire Distribution}

Organizations under study were large size organizations. Two conditions were applied to select these organizations: their experiences in knowledge management applications and their acceptance to participate. Forty five organizations belonging to three sectors (industrial; services and information technology) were selected based on a recommendation from Cairo Chamber of Commerce (CCC), Egypt. After personal contact, twenty seven organizations were agreed to participate in the study conditioning to hide their names. To assure the participants quick and correct response, the questionnaire copies submitted to supervisor persons. They have been asked to answer not more than 25 copies of the questionnaire. Some managers were very corporative and followed distribution of the questionnaire by themselves, but others didn't care about distributing the questionnaire. The total numbers of sent questionnaires were 675 copies and the received questionnaires were 485 copies with response rate $71.85 \%$. The majority of the participants are from organizations in the private sector (60.84\% working in private organizations and $39.16 \%$ are working in public organizations). Also, most of them are working in Services sector (37.53 \%) followed by IT sector 34.02\% and Industrial sector 28.45\%) as shown in Table 1.

Table 1 : Results of knowledge infrastructure capabilities

\begin{tabular}{|c|c|c|c|c|c|c|}
\hline \multirow{3}{*}{ Sector } & \multicolumn{4}{|c|}{ Organization Type } & \multirow{2}{*}{\multicolumn{2}{|c|}{ Total }} \\
\hline & \multicolumn{2}{|c|}{ Private } & \multicolumn{2}{|c|}{ Public } & & \\
\hline & $\begin{array}{c}\text { No. of } \\
\text { organizations }\end{array}$ & $\begin{array}{c}\text { No. of } \\
\text { respondents }\end{array}$ & $\begin{array}{c}\text { No. of } \\
\text { organizations }\end{array}$ & $\begin{array}{c}\text { No. of } \\
\text { respondents }\end{array}$ & $\begin{array}{c}\text { No. of } \\
\text { organizations }\end{array}$ & $\begin{array}{c}\text { No. of } \\
\text { respondents }\end{array}$ \\
\hline Services & 3 & 55 & 7 & 127 & 10 & 182 \\
\hline Industry & 5 & 87 & 3 & 51 & 8 & 138 \\
\hline IT & 8 & 153 & 1 & 12 & 9 & 165 \\
\hline Total & 16 & 295 & 11 & 190 & 27 & 485 \\
\hline
\end{tabular}

Twenty five questionnaires were randomly selected from the received questionnaires in each sector to use as control sample.

\section{Results and Discussion 6.1 Results}

The obtained results showing that the dimensions of knowledge management applications have different mean values according sector types as shown in Table 2. Pearson correlation was used to examine is there any correlation between knowledge management dimensions that include infrastructure; process and functions and organizational performance? The results show that the correlation coefficients are more than 0.7 ; it means that knowledge management dimensions have high significant correlation (strong positive correlation) with organizational performance.

The analysis results show that there is a strong positive correlation between knowledge management dimensions (infrastructure and process) and knowledge management functions. The results also show that there is a strong positive correlation between knowledge management functions and organizational performance as shown in Tables $3 \& 4$. 
Table 2 : Results of knowledge management applications

\begin{tabular}{|c|c|c|c|c|c|c|c|c|c|c|}
\hline \multirow{6}{*}{ 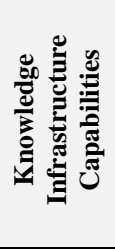 } & \multirow{2}{*}{ Item } & \multicolumn{3}{|c|}{ Service } & \multicolumn{3}{|c|}{ Industry } & \multicolumn{3}{|c|}{ IT } \\
\hline & & Mean & $\mathbf{I}_{\boldsymbol{i}}$ & KMI & Mean & $\mathbf{I}_{\boldsymbol{i}}$ & KMI & Mean & $\mathbf{I}_{\boldsymbol{i}}$ & KMI \\
\hline & Technology & 3.62 & 0.19 & \multirow{4}{*}{3.58} & 3.71 & 0.35 & \multirow{4}{*}{3.89} & 4.32 & 0.44 & \multirow{4}{*}{4.31} \\
\hline & Culture & 3.51 & 0.18 & & 3.77 & 0.13 & & 4.36 & 0.11 & \\
\hline & Structure & 3.44 & 0.21 & & 3.39 & 0.27 & & 4.21 & 0.19 & \\
\hline & Human resource & 3.66 & 0.42 & & 3.71 & 0.25 & & 4.33 & 0.26 & \\
\hline \multirow{6}{*}{ 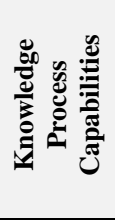 } & Item & Mean & $\mathbf{I}_{j}$ & KMI & Mean & $\mathbf{I}_{j}$ & KMI & Mean & $\mathbf{I}_{j}$ & KMI \\
\hline & Acquisitions & 3.54 & 0.18 & \multirow{5}{*}{3.52} & 3.58 & 0.15 & \multirow{5}{*}{3.73} & 4.19 & 0.18 & \multirow{5}{*}{4.32} \\
\hline & Conversions & 3.49 & 0.16 & & 3.67 & 0.19 & & 4.27 & 0.17 & \\
\hline & Application & 3.54 & 0.16 & & 3.85 & 0.25 & & 4.37 & 0.19 & \\
\hline & Protection & 3.43 & 0.25 & & 3.71 & 0.26 & & 4.24 & 0.28 & \\
\hline & Storing & 3.61 & 0.25 & & 3.76 & 0.15 & & 4.31 & 0.18 & \\
\hline \multirow{4}{*}{ 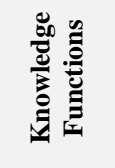 } & Item & Mean & $\mathbf{I}_{\mathbf{k}}$ & KMI & Mean & $\mathbf{I}_{\mathbf{k}}$ & KMI & Mean & $\mathbf{I}_{\mathbf{k}}$ & KMI \\
\hline & Creation & 3.52 & 0.20 & \multirow{3}{*}{3.48} & 3.63 & 0.30 & \multirow{3}{*}{3.64} & 4.15 & 0.30 & \multirow{3}{*}{4.18} \\
\hline & Sharing & 3.42 & 0.40 & & 3.58 & 0.35 & & 4.09 & 0.30 & \\
\hline & Utilization & 3.52 & 0.40 & & 3.70 & 0.35 & & 4.28 & 0.40 & \\
\hline \multicolumn{2}{|c|}{$\begin{array}{c}\text { Organizational } \\
\text { Performance }\end{array}$} & \multicolumn{3}{|c|}{3.83} & \multicolumn{3}{|c|}{4.02} & \multicolumn{3}{|c|}{4.46} \\
\hline
\end{tabular}

Table 3 : Correlation between KM Dimensions and KM Functions

\begin{tabular}{|l|c|}
\hline \multicolumn{1}{|c|}{ Item } & Correlation Coefficient \\
\cline { 2 - 2 } & KM Dimensions \\
\hline KM Functions & 0.999401 \\
\hline Creation & 0.999541 \\
\hline Sharing & 0.999991 \\
\hline Utilization & 0.990822 \\
\hline
\end{tabular}

Table 4 : Correlation between KM Dimensions and KM Functions

\begin{tabular}{|l|c|c|}
\hline \multirow{2}{*}{\multicolumn{1}{|c}{ Item }} & \multicolumn{2}{c|}{ Correlation Coefficient } \\
\cline { 2 - 3 } & $\begin{array}{c}\text { KM } \\
\text { Functions }\end{array}$ & $\begin{array}{c}\text { KM } \\
\text { Functions }\end{array}$ \\
\hline $\begin{array}{l}\text { Organizational } \\
\text { Performance }\end{array}$ & 0.996972 & 0.999401 \\
\hline Profitability & 0.998878 & 0.999991 \\
\hline Productivity & 0.999917 & 0.999541 \\
\hline Market Share & 0.995736 & 0.990822 \\
\hline Competitiveness & 0.982617 & 0.989719 \\
\hline Sales Growth & 0.992939 & 0.997136 \\
\hline Innovativeness & 0.984878 & 0.991443 \\
\hline Cost performance & 0.998511 & 0.999935 \\
\hline
\end{tabular}

\subsection{Framework Deployment}

Organizational performance can be calculated using the proposed framework after calculating the correction factors as follows:

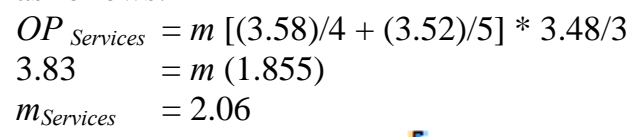

$\operatorname{OP}($ Services $)=2.06\left[\sum_{i=1}^{4}\left(X_{i} * E_{i}\right) / 4+\sum_{i=1}^{5}\left(Y_{f} * I_{l}\right) / 5\right] * \sum_{k=1}^{g}\left(Z_{k} * I_{k}\right) / 3$

$O P_{\text {Industry }}=m[(3.89) / 4+(3.73) / 5] * 3.64 / 3$

$4.02=m(2.09)$

$m_{\text {Industry }}=1.92$

$\operatorname{OP}($ Indiustry $)=1.92\left[\sum_{i=1}^{4}\left(X_{t} * I_{i}\right) / 4+\sum_{i=1}^{8}\left(Y_{i} * I_{f}\right) / 5\right] * \sum_{k=1}^{8}\left(Z_{k} * I_{k}\right) / 3$

$O P_{I T} \quad=m[(4.31) / 4+(4.32) / 5] * 4.18 / 3$

$4.46=m(2.71)$

$m_{I T} \quad=1.65$

$\operatorname{OP}(I T)=1.65\left[\sum_{i=1}^{4}\left(X_{t} * I_{i}\right) / 4+\sum_{i=1}^{5}\left(Y_{i} * I_{f}\right) / 5\right] * \sum_{k=1}^{8}\left(Z_{k} * I_{k}\right) / 3$ 
The framework is ready to use to assess (expect) the organizational performance based on knowledge management applications in each field. The results of the control sample are shown in Table 4.

The calculated and measured organizational performances for the three sectors are shown in Table 5.
The results show that the differences between calculated and measured organizational performances ranged between $0.4 \%$ and $1.8 \%$. It means that the framework can be used to expect the organizational performances based on knowledge management applications.

Table 4 : Results of control sample

\begin{tabular}{|c|c|c|c|c|c|c|c|c|c|c|}
\hline \multirow{6}{*}{ 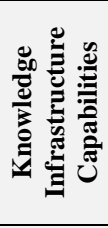 } & \multirow{2}{*}{ Item } & \multicolumn{3}{|c|}{ Service } & \multicolumn{3}{|c|}{ Industry } & \multicolumn{3}{|c|}{ IT } \\
\hline & & Mean & $\mathbf{I}_{\boldsymbol{i}}$ & KMI & Mean & $\mathbf{I}_{\boldsymbol{i}}$ & KMI & Mean & $\mathbf{I}_{i}$ & KMI \\
\hline & Technology & 3.40 & 0.19 & \multirow{4}{*}{3.51} & 3.93 & 0.35 & \multirow{4}{*}{3.72} & 4.34 & 0.44 & \multirow{4}{*}{4.33} \\
\hline & Culture & 3.59 & 0.18 & & 3.68 & 0.13 & & 4.38 & 0.11 & \\
\hline & Structure & 3.33 & 0.21 & & 3.45 & 0.27 & & 4.22 & 0.19 & \\
\hline & Human resource & 3.61 & 0.42 & & 3.72 & 0.25 & & 4.36 & 0.26 & \\
\hline \multirow{6}{*}{ 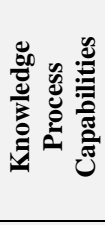 } & Item & Mean & $\mathbf{I}_{j}$ & KMI & Mean & $\mathbf{I}_{j}$ & KMI & Mean & $\mathbf{I}_{j}$ & KMI \\
\hline & Acquisitions & 3.53 & 0.18 & \multirow{5}{*}{3.63} & 3.77 & 0.15 & \multirow{5}{*}{3.74} & 4.18 & 0.18 & \multirow{5}{*}{4.29} \\
\hline & Conversions & 3.56 & 0.16 & & 3.72 & 0.19 & & 4.30 & 0.17 & \\
\hline & Application & 3.74 & 0.16 & & 3.71 & 0.25 & & 4.38 & 0.19 & \\
\hline & Protection & 3.64 & 0.25 & & 3.74 & 0.26 & & 4.25 & 0.28 & \\
\hline & Storing & 3.68 & 0.25 & & 3.76 & 0.15 & & 4.33 & 0.18 & \\
\hline \multirow{4}{*}{ 苾 } & Item & Mean & $\mathbf{I}_{\mathbf{k}}$ & KMI & Mean & $\mathbf{I}_{\mathbf{k}}$ & KMI & Mean & $\mathbf{I}_{\mathbf{k}}$ & KMI \\
\hline & Creation & 3.49 & 0.20 & \multirow{3}{*}{3.53} & 3.70 & 0.30 & \multirow{3}{*}{3.60} & 4.17 & 0.30 & \multirow{3}{*}{4.20} \\
\hline & Sharing & 3.45 & 0.40 & & 3.53 & 0.35 & & 4.11 & 0.30 & \\
\hline & Utilization & 3.62 & 0.40 & & 3.57 & 0.35 & & 4.29 & 0.40 & \\
\hline \multicolumn{2}{|c|}{$\begin{array}{l}\text { Organizational } \\
\text { Performance }\end{array}$} & \multicolumn{3}{|c|}{3.79} & \multicolumn{3}{|c|}{3.92} & \multicolumn{3}{|c|}{4.46} \\
\hline
\end{tabular}

Table 5 : Organizational performances

\begin{tabular}{|l|c|c|c|c|}
\hline \multirow{2}{*}{ Sector } & \multicolumn{4}{|c|}{ Organizational Performance } \\
\cline { 2 - 5 } & Calculated & Measured & Difference & 0.07 \\
\hline Services & 3.88 & 3.81 & 0.05 & $1.80 \%$ \\
\hline Industry & 3.87 & 3.92 & 0.02 & $0.30 \%$ \\
\hline IT & 4.44 & 4.46 & $0.40 \%$ \\
\hline
\end{tabular}

\section{Conclusion}

A critical issue in adoption of knowledge management initiatives is the preliminary preparation of the organization to accept, adopt, and utilize new knowledge management processes. Many organizations still view knowledge management as launching some software programs without adequate consideration of their organizational characteristics to ensure the success of their knowledge management initiatives. Wei, et al suggested further research to investigate the relationship between degrees of knowledge management implementation within an organization and corresponding increases in organizational performance. Therefore, the purpose of this work is to provide a conceptual framework to describe the KM dimensions and address its relationship with organizational performance ${ }^{[36]}$. The results show that there is positive correlation between knowledge management capabilities and organizational performance. These results indicate that the KM dimensions are well implemented in IT sector followed by Industrial and Services sectors. The highest dimension in Services sector that affects organizational performance is human resources and has mean value of 3.66; whereas, culture is the highest dimension in Industrial and IT sectors and has mean values of 3.77 ; and 4.36 respectively. In knowledge management process, the highest dimension in Services sector that affects organizational performance is storing and has mean value of 3.61; whereas, applications is the highest dimensions in Industrial and IT sectors and has mean values of 3.85; and 4.37 respectively. The results also show that the proposed framework can be used to assess organizational performance and also can be used as decision tool to decide which knowledge management capability should be improved.

\section{References}

[1] Zaim H., Tatoglu E. \& Zaim S., "Performance of knowledge management practices: a causal analysis", Journal of Knowledge Management, 2007, 11(6): 54-67.

[2] Lee Y. \& Lee S., "Capabilities, Processes, and Performance of Knowledge Management: A Structural Approach", Human Factors and Ergonomics in Manufacturing, 2007, 17(1): 21-41. [3] Gold A. Malhotra A. \& Segars A., "Knowledge management: an organizational capabilities perspective", Journal of Management Information Systems, 2001, 18(1):185-214.

[4] Fan Z., Feng B., Sun Y. \& Ou W., "Evaluating knowledge management capability of organizations: a fuzzy linguistic method", Expert Systems with Applications, 2009, 36: 3346-3354. 
[5] Aujirapongpan S., Vadhanasindhu P., Chandrachai A. \& Cooparat P., "Indicators of knowledge management capability for KM effectiveness", The journal of information and knowledge management systems, 2010, 40(2): 183-203.

[6] Chang T. \& Chuang S., "Performance implications of knowledge management processes: Examining the roles of infrastructure capability and business strategy", Expert Systems with Applications, 2011, 38: 6170-6178.

[7] Filemon A. \& Uriarte J., "Introduction to Knowledge Management”, ASEAN Foundation, Jakarta, Indonesia, 2008.

[8] Yeh Y., Lai S. \& Ho C., "Knowledge management enablers: a case study”, Industrial Management \& Data Systems, 2006, 106(6): 793-810.

[9] Chang T. \& Chuang S., "Performance Effects of Knowledge Management: Corporate Management Characteristics and Competitive Strategy Enablers", Asian Journal of Management and Humanity Sciences, 2009, 4(4): 181-199.

[10] Lee H. \& Choi B., "Knowledge management enablers, processes, and organizational performance: An integrative view and empirical examination", Journal of Management Information Systems, 2003, 20(1): 179-228.

[11] Liao C. \& Chuang S., "Exploring the Role of Knowledge Management for Enhancing Firm's Innovation and Performance", $39^{\text {th }}$ Hawaii International Annual Conference on System Sciences, USA, 2006: 1-10.

[12] Liao C., Wang H., Chuang S., Shih M., \& Liu C., "Enhancing knowledge management for R\&D innovation and firm performance: An integrative view", African Journal of Business Management, 2010, 4(14): 3026-3038.

[13] Mills A. \& Smith T., "Knowledge management and organizational performance: a decomposed view", Journal of Knowledge Management, 15(1): 156-171.

[14] Nguyen Q., Neck P., \& Nguyen T., "The Critical Role of Knowledge Management in Achieving and Sustaining Organizational Competitive Advantage", International Business Research, 2009, 2(3): 3-16.

[15] Smith T., Mills A. \& Dion P., "Linking Knowledge Management Capabilities to the Business Strategy for Organizational Effectiveness", International Journal of Knowledge Management, 2010, 6(3): 22-43.

[16] Theriou N., Maditinos D., \& Theriou G., "Knowledge Management Enabler Factors and Firm Performance: An empirical research of the Greek medium and large firms". International Conference on Applied Business and Economics, Technological Educational Institute of Kavala, Kavala, Greece, 2010: 1-20.

[17] Lee L. \& Sukoco B., “The effects of entrepreneurial orientation and knowledge management capability on organizational effectiveness in Taiwan: the moderating role of social capital”, International Journal of Management, 2007, 24(3): 549-573.

[18] Chan I. \& Chao C., "Knowledge management in small and medium-sized enterprises", Communications of the ACM, 2008, 51(4): 83-88.

[19] Cui A. Griffith D. \& Cavusgil S., "The Influence of Competitive Intensity and Market Dynamism on Knowledge Management Capabilities of MNC Subsidiaries”, Journal of International Marketing, 2005, 13(3): 32-53.

[20] Kasim R. (2010) "The Relationship of Knowledge Management Practices, Competencies and the Organizational Performance of Government Departments in Malaysia", International Journal of Human and Social Sciences, 2010, 5(4): 219-225.

[21] Zahra S. \& George G., "Absorptive capacity: A review, reconceptualization, and extension”, Academy of Management Review, 2002, 27(2): 185-203.
[22] Bhatt G., "Management strategies for individual knowledge and organizational knowledge", Journal of Knowledge Management, 2002, 6(2): 31-39.

[23] Daud S. \& Yusuf W., "An Empirical Study of Knowledge Management Processes in Small and Medium Enterprises", Communications of the IBIMA, 2008, 4: 169-177.

[24] Sarin S, \& McDermott C., "The effect of team leader characteristics on learning, knowledge application, and performance of cross-functional new product development teams”, Decision Science, 2003, 34(2): 707-39.

[25] Weisberg R. "Expertise and reason in creative thinking: evidence from case studies and the laboratory". In: Kaufman J. \& Baer J, "Creativity and Reason in Cognitive Development. Cambridge”, Cambridge University Press; 2006.

[26] Lee M. \& Lan Y., "Toward a unified knowledge management model for SMEs", Expert Systems with Applications, 2011, 38: 729-735.

[27] Argote L, McEvily B, \& Reagans R., "Managing knowledge in organizations: an integrative framework and review of emerging themes”, Management Science, 2003, 49(4): 571-582.

[28] Nonaka I., Von-Krogh G., \& Voelpel S., “Organizational knowledge creation theory: Evolutionary paths and future advances”, Organization Studies, 2006, 27: 1179-1208.

[29] Alavi M. \& Leidner D., "Review: knowledge management and knowledge management systems: Conceptual foundations and research issues”, MIS Quarter, 2001, 25(1): 107-136.

[30] Anantatmula V. \& Kanungo S., "Structuring the underlying relations among the knowledge management outcomes”, Journal of Knowledge Management, 2006, 10(4): $25-42$.

[31] Chen M. Huang M. \& Cheng Y., “Measuring knowledge management performance using a competitive perspective: An empirical study”, Expert Systems with Applications, 2009, 36: 8449-8459.

[32] Harrim H., "Learning Organization and Organizational Performance Relationship: Empirical Study of Pharmaceutical Firms In Jordan", Jordan Journal of Business Administration, 2010, 6(3): 405-424.

[33] Lee K., Lee S. \& Kang I., "KMPI: measuring knowledge management performance”, Information \& Management, 2005, 42(3): 469-482.

[34] Zack M., McKeen J. \& Singh S., "Knowledge management and organizational performance: an exploratory analysis", Journal of Knowledge Management, 2009, 13(6): 392-409.

[35] Bhatti W., Zaheer A. \& Rehman K., "The effect of knowledge management practices on organizational performance: A conceptual study”, African Journal of Business Management, 2011, 5(7): 2847-2853.

[36] Wei Z., Baiyin Y. \& Gary N., "Linking organizational culture, structure, strategy, and organizational effectiveness: Mediating role of knowledge management”, Journal of Business Research, 2010, 63: 763-771.

Abdel Nasser H. Zaied is a Vice-dean for education and students affairs, College of Computers and Informatics, Zagazig University, Egypt. He previously worked as an Associate Professor of Industrial Engineering, Zagazig University Egypt; an assistant professor of Technology Management, Arabian Gulf University, Bahrain; and as visiting professor at Oakland University, USA. He supervised $8 \mathrm{PhD}$. thesis and 37 MSc. thesis, and examined 32 MSc thesis. He published fifteen research papers in International and Regional Journals and 22 research papers in International and National conferences. His areas of research are: Systems Analysis and Design; Information Security; Knowledge Management; Quality Management Systems and project Management. 
Appendix (I): Questionnaire Statements

\begin{tabular}{|c|c|c|c|c|c|}
\hline \multicolumn{6}{|c|}{ Statements of knowledge infrastructure capabilities } \\
\hline \multirow{2}{*}{$\begin{array}{c}\text { Relative } \\
\text { Importance }\end{array}$} & technology & structure & culture & \multirow[t]{2}{*}{ human resources } & Total \\
\hline & & & & & $100 \%$ \\
\hline \multicolumn{6}{|c|}{ 1. Our organization provides IT support for collaborative works regardless of time and place } \\
\hline \multicolumn{6}{|c|}{ 2. $\quad$ Our organization provides IT support for communication among organization members. } \\
\hline \multicolumn{6}{|c|}{ 3. We have easy computer access to the information we need to do our jobs. } \\
\hline \multicolumn{6}{|c|}{ 4. $\quad$ Our organization provides IT support (e.g., groupware) for information acquisition. } \\
\hline \multicolumn{6}{|c|}{ 5. $\quad$ Our organization provides IT support (e.g., intranet) for information sharing. } \\
\hline \multicolumn{6}{|c|}{ 6. Our organization provides IT support for systematic storing. } \\
\hline \multicolumn{6}{|c|}{ 7. Our organization provides various formal training programs for performance of duties. } \\
\hline \multicolumn{6}{|c|}{ 8. Our organization provides job rotation for employees to develop themselves } \\
\hline \multicolumn{6}{|c|}{ 9. There is a willingness to collaborate across organizational units within our organization. } \\
\hline \multicolumn{6}{|c|}{ 10. Our organization members are helpful. } \\
\hline \multicolumn{6}{|c|}{ 11. Our organization members are generally trustworthy } \\
\hline \multicolumn{6}{|c|}{ 12. Our organization members have reciprocal faith in others' behaviors to work toward organizational goals. } \\
\hline \multicolumn{6}{|c|}{ 13. Our organization members are encouraged to make their own decisions. } \\
\hline 14. Our organ & tion members & an make decis & s without appr & & \\
\hline 15. Our organ & ation members & o not need to & their supervis & efore action. & \\
\hline 16. In our org & ization there a & many activiti & hat are not cor & by some formal & \\
\hline 17. In our org & zation memb & make their o & rules on the jo & & \\
\hline 18. In our org & ization rules a & procedures a & ypically writte & & \\
\hline 19. Our organ & tion members & an understand & t only their ow & sks but also others' tasks. & \\
\hline 20. Our organ & tion members & e specialists & heir own part. & & \\
\hline 21. Our orgar & tion members & an perform th & own task effec & ly without regard to environ & changes. \\
\hline 22. Our organ & tion members & ink that their & n tasks are the & ion employing knowledge. & \\
\hline $\begin{array}{l}\text { 23. } \begin{array}{l}\text { Our organ } \\
\text { departmel }\end{array}\end{array}$ & $\begin{array}{l}\text { tion member } \\
\text { nembers. }\end{array}$ & an communic & well not only & their department members & with other \\
\hline 24. Our organ & tion members & re supportive & knowledge sh & g \& creation. & \\
\hline & & Statements o & nowledge pro & capabilities & \\
\hline Relative & acquisition & conversion & application & protections & Total \\
\hline Importance & & & & & $100 \%$ \\
\hline 1. Our organ & tion has proce & es for acquiri & knowledge abc & jur customers. & \\
\hline 2. Our organ & tion has proce & es for genera & new knowled & rom existing knowledge. & \\
\hline 3. Our organ & tion has proce & es for acquiri & knowledge abc & ur suppliers. & \\
\hline 4. Our organ & tion uses feed & ck from proje & to improve su & quent projects. & \\
\hline 5. Our organ & tion has proce & es for acquiri & knowledge abc & ompetitors within our ind & \\
\hline 6. Our organ & tion has proce & es for exchan & g knowledge $\mathrm{b}$ & een individuals. & \\
\hline 7. Our organ & ation has proce & es for conver & knowledge in & he design of new products/s & \\
\hline 8. Our organ & tion has proce & es for filterin & nowledge. & & \\
\hline 9. Our organ & tion has proce & es for transfe & g organization & nowledge to individuals. & \\
\hline 10. Our orgar & tion has proce & es for absorb & knowledge fro & ndividuals into the organi & \\
\hline 11. Our organ & tion has proce & es for organiz & knowledge. & & \\
\hline 12. Our organ & tion has proce & es for replaci & outdated know & & \\
\hline 13. Our organ & tion has proce & es for applyir & knowledge lear & from mistakes. & \\
\hline 14. Our organ & tion has proce & es for applyir & nnowledge Lea & from experiences. & \\
\hline 15. Our organ & tion has proce & es for using $\mathrm{k}$ & wledge to solv & w problems. & \\
\hline 16. Our organ & tion uses kno & edge to impro & efficiency. & & \\
\hline 17. Our organ & tion quickly a & lies knowled & o critical com & ive needs. & \\
\hline 18. Our organ & tion Makes k & wledge acces & e to those who & dit. & \\
\hline 19. Our organ & tion has proce & es to protect & wledge from $\mathrm{i}$ & ropriate use inside the orga & \\
\hline 20. Our organ & tion has proce & es to protect & wledge from i & oropriate use outside the org & \\
\hline 21. Our organ & tion has incer & ves that encou & se the protectio & knowledge. & \\
\hline 22. Our organ & tion has techr & ogy that restr & access to som & urces of knowledge. & \\
\hline 23. Our orgar & ation has exter & ve policies an & rocedures for & ecting trade secrets. & \\
\hline 24. Our orgar & ation Knowled & that is restric & is clearly ider & & \\
\hline 25. Our organ & tion stresses I & resenting kno & edge in docum & , databases, and software. & \\
\hline 26. I always $\mathrm{f}$ & the precise $\mathrm{k}$ & wledge I neec & & & \\
\hline 27. I always $\mathrm{f}$ & the sufficien & nowledge to $\epsilon$ & ble me to do $\mathrm{m}$ & sks. & \\
\hline 28. The speci & knowledge th & I need resides & ith the experts & er than being stored in the $p$ & \\
\hline 29. The know & ge stored in $\mathrm{t}$ & portal cannot & directly applie & ithout extensive modificatic & \\
\hline 30. The stor & wwledge in & organizatic & quite impor & elevant and latest. & \\
\hline & & Stateme & of knowledg & nctions & \\
\hline
\end{tabular}




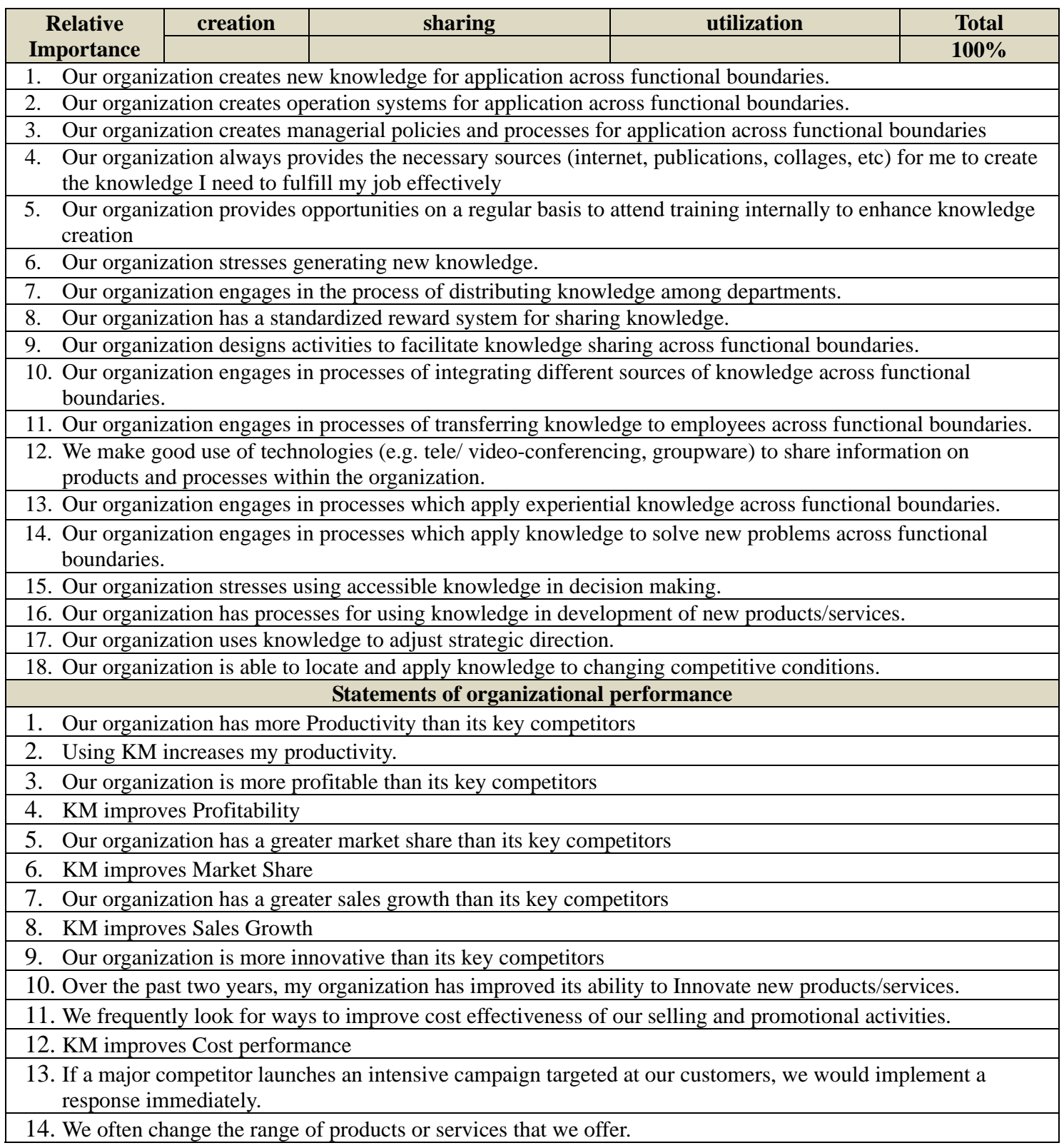

